\title{
O materialismo histórico dialético e a historicidade da sociedade em Marx (1818-
}

\section{3)}

\author{
Dialectical historical materialism and the historicity of society in Marx (1818-1883) \\ El materialismo histórico dialéctico y la historicidad de la sociedad en Marx (1818-1883)
}

Recebido: 15/01/2021 | Revisado: 18/01/2021 | Aceito: 28/01/2021 | Publicado: 04/02/2021

\author{
Wagner dos Reis Marques Araújo \\ ORCID: https://orcid.org/0000-0003-0793-0043 \\ Universidade do Estado de Minas Gerais, Brasil \\ E-mail: marquesreis@hotmail.com \\ Antonio Marcos de Oliveira Siqueira \\ ORCID: https://orcid.org/0000-0001-9334-0394 \\ Universidade Federal de Viçosa, Brasil \\ E-mail: antonio.siqueira@ufv.br
}

\begin{abstract}
Resumo
Este texto é resultado de uma breve discussão acerca do materialismo-histórico dialético como uma abordagem que inaugura a noção de historicidade na Modernidade, e do método dialético de Marx como uma base teóricometodológica para análise e compreensão não somente do modo de produção capitalista como da história social. Parte-se da ideia Marxista de que a ação do homem sobre a natureza, ou seja, o trabalho é o elemento definidor da espécie humana e a luta de classe o motor da história, que são ações que se efetivam de forma dialética. Defende-se, aqui, uma teoria da história desenvolvida na obra do autor a partir dos conceitos, a saber, forças produtivas e relações sociais de produção.
\end{abstract}

Palavras-chave: Karl Marx; Forças produtivas; Relações sociais de produção; Historicidade.

\begin{abstract}
This text is the result of a brief discussion about dialectical historical-materialism as an approach that inaugurates the notion of historicity in Modernity, and of Marx's dialectical method as a theoretical-methodological basis for analysis and understanding not only of the capitalist mode of production as of social history. It starts with the Marxist idea that man's action on nature, that is, work is the defining element of the human species and class struggle is the engine of history, which are actions that are carried out in a dialectical way. Here we defend a theory of history developed in the author's work based on concepts, namely, productive forces and social relations of production.
\end{abstract}

Keywords: Karl Marx; Productive forces; Social relations of production; Historicity.

\section{Resumen}

Este texto es el resultado de una breve discusión sobre el histórico-materialismo dialéctico como enfoque que inaugura la noción de historicidad en la Modernidad, y del método dialéctico de Marx como base teóricometodológica para el análisis y comprensión no solo del modo de producción capitalista como de la historia social. Se parte de la idea marxista de que la acción del hombre sobre la naturaleza, es decir, el trabajo es el elemento definitorio de la especie humana y la lucha de clases es el motor de la historia, que son acciones que se llevan a cabo de forma dialéctica. Aquí defendemos una teoría de la historia desarrollada en la obra del autor basada en conceptos, a saber, fuerzas productivas y relaciones sociales de producción.

Palabras clave: Karl Marx; Fuerzas productivas; Relaciones sociales de producción; Historicidad.

\section{Introdução}

Karl Marx (1818-1883) imortalizou-se como um dos fundadores do pensamento sociológico ao propor uma nova perspectiva de análise e interpretação da realidade social. Nascido em 1818, no contexto do Império Alemão, em Trier, Prússia Renana, ele foi o segundo dos oito filhos de uma família de origem judaica pertencente à burguesia. Marx inicia, aos 17 anos, seus estudos de Direito na Universidade de Bonn e, em 1841, aos 23 anos, torna-se doutor em Filosofia pela Universidade de Jena, ocupando-se dos filósofos gregos materialistas, Demócrito e Epicuro. 
As formulações de Karl Marx acerca da historicidade do homem e de sua capacidade de superar histórica e socialmente as determinações materiais lançam por terra análises que restringem os seus estudos à sociedade capitalista. A historicidade do ser social de Marx não pode ser reduzida a determinados espaços sociais historicamente estáticos, por exemplo, à compreensão exclusiva da sociedade capitalista (Augusto \& Carcanholo, 2014).

Marx, seguramente, não é um teórico restrito apenas às análises do capitalismo, tampouco a sua perspectiva se restringe à economia política. A teoria social inaugurada por Marx, e idealizada com base nas análises que fez dos distintos modos de produção, confirma que os modos como o homem atua sobre a natureza, transformando-a para sua sobrevivência e perpetuação da espécie, são desenvolvidos histórica e socialmente e, por conseguinte, aperfeiçoados e transferidos às gerações que se sucedem.

Embora o século XIX seja o contexto histórico a partir do qual Marx escreve e busca compreender, a perspectiva teórico-metodológica que desenvolve, e apresentada em sua obra, busca estabelecer leis gerais para a análise do capitalismo e do seu funcionamento. Tal perspectiva, portanto, parte da proposição que a história não deriva de princípios abstratos, ou seja, não é resultado das ideias do homem, mas da materialidade humana.

Marx foi um dos herdeiros do ideário iluminista e, como os pensadores de seu tempo, creditava à razão humana o caminho capaz de construir uma sociedade mais justa e propícia ao desenvolvimento do homem. À vista disso, ele dialogou com as principais correntes de pensamento da época, tecendo-lhes críticas bem contundentes sem, a despeito disso, romper definitivamente com elas. Todavia, contrapôs-se, já em seus primeiros trabalhos intelectuais, ao idealismo de Hegel (invertendo a dialética deste idealista) e ao positivismo (não aderindo às leis naturais como causa final da sociedade), construindo um arcabouço teórico e conceitual que, posteriormente, elevou a sua obra ao patamar máximo da teoria social.

O marco temporal das investigações e interpretações realizadas por Marx foi o início do advento da modernidade (Giddens, 2005). Em suas obras, ele detém-se às análises e explicações das mudanças e dos conflitos que se erigiram num período marcado por grandes revoluções. Marx foi quem definiu a categoria trabalho em termos materiais e históricos.

Nesse sentido, segundo aponta Emir Sader (2007), na interpretação Marxista da história “a compreensão do processo de trabalho permite, ao mesmo tempo, a compreensão da origem da separação da teoria e da prática e das formas que permitem sua reconexão" (Sader, 2007, p. 15). Ele também partiu do pressuposto que todo fenômeno econômico é, igualmente, um fenômeno social, uma vez que, a sua perspectiva aponta que a existência de um sistema econômico presume, igualmente, a existência de uma ordem social que o sustente material e ideologicamente (Giddens, 2005).

A Inglaterra foi o pano de fundo das abordagens de Marx acerca das dinâmicas das transformações sociais e culturais encerradas pelo advento da modernidade, onde ele se detém a analisar os modos de produção capitalista. Com isso, o seu projeto de compreensão da sociedade, prosseguiu à análise das formas como os homens produzem e reproduzem as suas condições de exigência. Segundo Anav (2017, p. 2017), Marx “buscava compreender o mundo para transformá-lo".

Tomando por base a abordagem materialista histórica, Marx analisava a produção social em um dado estágio de desenvolvimento da sociedade humana. E, a partir de suas constatações, buscou compreender como os seres humanos constituídos socialmente produzem seus meios de vida. Portanto, ele constatou que a produção e a reprodução da vida material que se efetivam por meio do trabalho confirmam a centralidade do trabalho na vida do ser social e de constituidor da história dos homens, sobretudo através da luta de classes.

Por enquanto, esta discussão limitou-se a, inicialmente, situar aspectos acerca da trajetória de Marx e do contexto histórico do qual escreve.

Deste ponto em diante, discutem-se os termos forças produtivas e relações sociais de produção como categorias (e seu modo de relação), que são fundamentais para se compreender a historicidade na perspectiva Marxista. O fenômeno históricosocial passa, à vista disso, a ser percebido com base nas relações objetivas concretas de modo que a parti do século XIX “o 
sujeito do conhecimento já não é o sujeito transcendental, e sim os homens concretos, historicamente determinados" (Alves et al., 2014, p. 90).

\section{Metodologia}

Este texto é resultado de uma pesquisa de cunho bibliográfico visando identificar uma teoria da história desenvolvida na obra de Karl Max a partir da discussão dos conceitos, a saber, forças produtivas e relações sociais de produção. Os dados foram obtidos através análise hermenêutica das obras: Manuscritos: economía y filosofia (1974), A miséria da filosofia (1985), Manifesto do Partido Comunista (2004) e A Ideologia Alemã (2007), sendo as duas últimas obras escritas em parceria com Friedrich Engels.

Enquanto método de análise, a hermenêutica contribui para a pesquisa bibliografia na nas ciências sociais, pois proporciona um caminho seguro na interpretação de textos complexos, ou seja, é um método mediador do conhecimento trazendo à luz fatos, dados e relações teóricas. Optou-se pela pesquisa bibliográfica por permitir que o estudo seja desenvolvido "a partir de material já elaborado, constituído principalmente de livros e artigos científicos” (Gil, 2008, p. 50).

Justifica-se, pois a pesquisa bibliográfica se torna particularmente imprescindível, conforme orienta Gil (2008), quando o problema de pesquisa abrange dados dispersos, bem como também é indispensável nos estudos históricos. Para a análise, procedeu-se o método hermenêutico "como uma teoria geral da interpretação, tomou como um dos temas básicos de investigação a relação entre vida e obra" (Alves et al., 2014, p. 182). Partiu-se, também, leitura crítica de estudos que trazem análises de síntese da obra de Karl Marx, sobretudo do materialismo histórico dialético, bem como as contribuições e limites teóricos-metodológicos.

\section{Resultados e Discussão}

Segundo especialistas, a teoria da história é desenvolvida ao longo de toda a obra de Marx. De fato, pode-se afirmar que ela está presente já nos seus primeiros escritos, e A Ideologia Alemã é indicada como sendo o ponto de partida dessa teoria. Sobre tal afirmação Emir Sader aponta que essa "é a primeira obra em que a articulação das categorias essenciais da dialética Marxista emerge madura, à superfície" (Sader, 2007, p. 15).

Seguramente, em A Ideologia Alemã, Marx e Engels apresentam pela primeira vez na história do pensamento filosófico, uma "teoria explicativa das condições históricas de produção e reprodução da vida dos homens" (Sader, 2007, p. 13). Onde, a estrutura de uma sociedade depende do estado de desenvolvimento de suas "forças produtivas" e reciprocamente das "relações sociais de produção" as quais são correspondentes (Marx \& Engels, 2007). Marx \& Engels (2007) assinalam logo de início, que para se compreender as forças produtivas é preciso partir do primeiro pressuposto da história da sociedade, que é a reprodução material dos homens (Marx \& Engels, 2007).

Trata-se, pois, de um movimento dialético, onde as forças produtivas são constituídas a partir da relação homem/natureza, já as relações sociais de produção são estabelecidas na relação homem/processo produtivo. Isto é, as forças produtivas são desenvolvidas diante dos “antagonismos de classe” que se dão na produção (Marx, 1985). E com isso a luta de classes que visa superar uma relação de produção.

Nisso consiste a síntese materialista da história na obra de Marx, onde a categoria forças produtivas "nos permite desfazer dois equívocos comuns na interpretação determinista do materialismo histórico: sua redução a conteúdo material como distinto e separado da forma social e sua redução aos meios de produção" (Augusto \& Carcanholo, 2014, p. 16). Vejamos, pois, deste ponto em diante, como o autor propõe o materialismo histórico da sociedade. 


\subsection{O materialismo histórico-dialético e a historicidade da sociedade}

A materialidade do mundo não pode ser pensada somente a partir da forma como os homens se organizam socialmente, tampouco se define o materialismo histórico exclusivamente pelos meios de produção. Marx "aponta para a origem histórica da relação social, reconstituindo seus diferentes elementos" (Martins, 2012, p. 76).

Destarte, as forças produtivas e as relações sociais de produção são processos interdependentes, e conceitualmente têm uma finalidade analítica de modo a tornar inteligível a realidade (Aron, 2000; Anav, 2017). O primeiro termo refere-se, portanto, à ação transformadora do homem sobre a natureza, que busca extrair dessa, em um dado momento da história, os bens necessários à sobrevivência e perpetuação da espécie. O segundo consiste, pois, nas formas de divisão e de distribuição dos meios de produção (solo, ferramentas, máquinas, insumos, capital, etc.) e também do produto, bem como determinam a forma como se dá a divisão social do trabalho.

Por isso, Marx e Engels afirmavam que os homens coincidem com sua produção, ou seja, tanto "o que eles produzem quanto com a maneira como produzem" (Marx \& Engels, 2007, p. 11). Assim, em sua idealização materialista da história, Marx, portanto, propõe uma abordagem acerca das dinâmicas das transformações sociais, onde defende que os conflitos entre classes sociais antagônicas são o motor da história da humanidade e, ainda, os homens na sua relação com o mundo se autoproduzem (Marx, 1985).

Em 1848, Marx e Engels publicaram o Manifesto do Partido Comunista, escrito panfletário de caráter político, que convocava os trabalhadores para uma revolução operária e socialista, em meio a uma revolução republicana na França. Nesses escritos, eles apresentam os princípios de sua teoria analítica - denominado "materialismo histórico dialético" -, definindo os conceitos de "consciência de classe" e "luta de classes", que são imprescindíveis para se compreender a concepção de história dos autores. Desta concepção, cabe destacar:

A história de todas as sociedades que existiram até hoje é a história da luta de classes. Homem livre e escravo, patrício e plebeu, barão e servo, mestres e companheiros, numa palavra, opressores e oprimidos, sempre estiveram em constante oposição uns aos outros, envolvidos numa luta ininterrupta, ora disfarçada, ora aberta, que terminou sempre ou com uma transformação revolucionária de toda a sociedade, ou com o declínio comum das classes em luta. (Marx \& Engels, 2004, p. 45).

De acordo com tal concepção, a história é o processo de criação, recriação e satisfação contínuas das necessidades do homem na sua relação com o mundo, isto é, a forma como produzem e autoproduzem continuamente a sociedade. Logo, a luta de classes seria o motor da história social, ou seja, o princípio gerador das transformações ocorridas ao logo da história da humanidade através da sucessão de gerações (Marx \& Engels, 2004).

Em A Miséria da Filosofia, obra publicada em 1847, Marx aponta a dimensão material da história e o caráter transitório das categorias, onde dá continuidade a sua ruptura com o idealismo.

Os homens produzem também, conforme as suas faculdades produtivas, as relações sociais nas quais produzem [por exemplo,] a seda e o tecido. E, ainda, [..] que produzem as relações sociais segundo a produção material, criam também as ideias, as categorias, isto é, as expressões abstratas ideias destas mesmas relações sociais. Portanto, estas categorias são tão pouco eternas quanto as relações que expressam. São produtos históricos e transitórios. (Marx, 1985, p. 212).

Para Marx, as condições de produção estruturadas na sociedade moderna se generalizariam a todas as sociedades humanas. No entanto, Marx ressalva que tais condições não se consolidariam como um modelo definitivo, pois seriam superadas do mesmo modo que as formas produtivas anteriores. Logo, o modelo capitalismo seria substituído (crise, superação e substituição) pelo comunismo, uma vez que, todo fenômeno cultural ou social é efêmero, transitório e histórico (Marx, 1985). 
Em síntese, isso significa que os homens adquirem novas forças produtivas, transformando o seu modo concreto de produção e reprodução social, modificando as suas relações econômicas a cada modo de produção que se sucede (Marx, 1985). Conforme aponta o próprio Marx (1985), a sociedade capitalista, marcada pela intensificação dos antagonismos entre as classes revolucionárias (proletariado e a burguesia industrial), levaria aquela formação social constituída com base na divisão social do trabalho a superar o regime produtivo através da luta de classes.

Tomando por base tais ideias, Marx vai defender que tanto a análise dos processos econômicos que se sucedem na sociedade humana quanto a conceitualização realizada para a sistematização de sua compreensão devem considerar a historicidade fenômenos. Tal questão aparece nas críticas tecidas por Marx aos economistas da época que não reconheciam a historicidade dos fenômenos que se manifestavam na sociedade capitalista (Aron, 2000).

Vejamos, conforme Marx, como se constitui em um determinado estágio do desenvolvimento da história dos homens, a produção social dos indivíduos com base no materialismo histórico dialético.

Independentemente do estágio social, os homens vivem em meio às necessidades de produção e reprodução da espécie. Segundo Marx (1974), todos os seres viventes buscam assegurar a sua existência e perpetuar a espécie, porém, os seres humanos procuram dominar a natureza e estabelecer relações sociais. Logo, produzem artefatos, ferramentas, desenvolvem técnicas e as transmitem às próximas gerações, por estes aspectos, humanizam a natureza e a si mesmos: “os homens, ao desenvolverem sua produção e seu intercâmbio materiais, transformam também, com esta sua realidade, seu pensar e os produtos de seu pensar. Não é a consciência que determina a vida, mas a vida que determina a consciência” (Marx \& Engels, 2007, p. 94).

Nos Manuscritos Econômico-filosóficos, de 1844, texto escrito de forma ensaística, Marx é enfático na proposição acerca do caráter indissociável do trabalho humano da vida em sociedade.

Enquanto o homem produz inclusive livre da necessidade física e só produz realmente liberado dela; o animal produz somente a si mesmo, enquanto o homem reproduz a natureza inteira; o produto do animal pertence imediatamente a seu corpo físico, enquanto o homem enfrenta-se livremente com seu produto $\mathrm{O}$ animal produz unicamente segundo a necessidade e a medida da espécie a que pertence, enquanto o homem sabe produzir segundo a medida de qualquer espécie e sabe sempre impor ao objeto a medida que lhe é inerente; por isso o homem cria também segundo as leis da beleza. (Marx, 1974, p. 112).

À vista disso, o trabalho em seu aspecto social, que é o resultado do esforço conjunto dos membros de uma comunidade humana, teria como objetivos últimos a manutenção e a satisfação da vida material e simbólica, e o desenvolvimento da sociedade. Por este aspecto, o trabalho humano é uma realidade indissociável da vida social e, por ser uma construção social, passa por transformações.

Em A Ideologia Alemã (escrito entre 1846 e 1847), Marx e Engels desenvolvem a tese da concepção materialista da história ${ }^{1}$, e rompem por vez com sua filiação intelectual hegeliana:

O primeiro pressuposto de toda a existência humana e também, portanto, de toda a história, a saber, [é] o pressuposto de que os homens têm de estar em condições de viver para poder "fazer. Mas, para viver, precisa-se, antes de tudo, de comida, bebida, moradia, vestimenta e algumas coisas mais. O primeiro ato histórico é, pois, a produção dos meios para a satisfação dessas necessidades, a produção da própria vida material, e este é, sem dúvida, um ato histórico, uma

\footnotetext{
${ }^{1}$ Cf. Marx \& Engels: "não se parte daquilo que os homens dizem, imaginam ou representam, tampouco dos homens pensados, imaginados e representados para, a partir daí, chegar aos homens de carne e osso; parte-se dos homens realmente ativos e, a partir de seu processo de vida real, expõe-se também o desenvolvimento dos reflexos ideológicos e dos ecos desse processo de vida. Também as formações nebulosas na cabeça dos homens são sublimações necessárias de seu processo de vida material, processo empiricamente constatável e ligado a pressupostos materiais" (Marx \& Engels, 2007, p. 94).
} 
condição fundamental de toda a história, que ainda hoje, assim como há milênios, tem de ser cumprida diariamente, a cada hora, simplesmente para manter os homens vivos. (Marx \& Engels, 2007, p. 32 - 33).

No processo de apropriação da natureza, os homens/mulheres a modificam e, através do processo criativo, constroem ferramentas e novos objetos para mediar a sua relação com o mundo natural. Nesse sentido, ao buscar atender as suas necessidades materiais de subsistência (físicas e naturais), os homens produzem e reproduzem seus meios de vida e, sendo desse modo, eles procuram controlar e transformar os meios naturais (Marx \& Engels, 2007).

Por um processo continuo e histórico, os homens "recriam a si próprios e reproduzem sua espécie num processo que é continuamente transformado pela ação das sucessivas gerações” (Oliveira \& Quintaneiro, 2007, p. 32). Isto quer dizer que, “os homens, ao desenvolverem sua produção e seu intercâmbio materiais, transformam também, com esta sua realidade, seu pensar e os produtos de seu pensar. Não é a consciência que determina a vida, mas a vida que determina a consciência” (Marx \& Engels, 2007, p. 94).

Marx e Engel (2007) afirmam que a produção de meios para subsistência humana é o primeiro pressuposto de toda existência do homem, ou seja, o princípio fundamental de toda a história humana. Assim, segundo Marx e Engels (2007), uma vez satisfeitas as primeiras necessidades (a ação de satisfazê-las e os instrumentos de satisfação já tendo sido adquiridos), esta etapa conduzirá a novas necessidades, por conseguinte, a produção de novas necessidades é o primeiro ato histórico do homem.

É supérfluo acrescentar que todos os homens não livres para escolher as suas forças produtivas - base de toda sua história - pois toda força produtiva é uma força adquirida, produto de uma atividade anterior. Portanto, as forças produtivas são o resultado da energia prática dos homens, mas essa mesma energia é circunscrita pelas condições em que os homens se acham colocados, pelas forças produtivas já adquiridas, pela forma social anterior, que não foi criada por e é produto da geração precedente. O simples fato de cada geração posterior deparar-se com forças produtivas adquiridas pelas gerações precedentes, que lhe servem de matéria-prima para as novas produções, cria na história dos homens uma conexão, cria uma história da humanidade, que é tanto mais a história da humanidade quanto mais as forças produtivas dos homens e, por conseguinte, as suas relações sociais adquiriram maior desenvolvimento. Consequência disso: a história social dos homens é sempre a história do seu desenvolvimento individual, tenham ou não consciência dos fatos. (Marx, 1985, p. 206 - 207).

Na medida em que as necessidades são ampliadas, o homem gera, porém, novas relações sociais que intervém no desenvolvimento histórico. De modo que a ação do homem sobre o mundo natural é, segundo esta perspectiva, expressa no termo "forças produtivas", que pretende explicar o estágio de domínio do homem sobre a natureza:

Portanto, as formas da economia sob as quais os homens produzem, consomem e fazem trocas são transitórias $e$ históricas. Ao adquirir novas forças produtivas, os homens transformam o seu modo de produção e, com ele, as relações econômicas necessárias aquele modo de produção determinado. (Marx, 1985, p. 207).

Na produção (re) produção da própria vida material o homem produção novas necessidades que, por sua vez, levamno a estabelecer outras relações sociais quando as suas necessidades são ampliadas. Tais aspectos são processuais e coexistem desde as origens da história humana e dos primeiros homens (Marx \& Engels, 2007). Se não fosse dessa forma, hoje os homens viveriam como há milhares de anos, uma vez que, conforme a concepção materialista: “As relações materiais formam a base de todas as suas relações. Estas relações materiais nada mais são que as formas necessárias nas quais se realizam a sua realidade material e individual" (Marx, 1985, p. 207).

Na produção capitalista, a divisão social do trabalho reflete, portanto, os modos de estratificação mais abrangentes da sociedade, produzindo desigualdades de "distribuição" dos instrumentos de produção (e distribuição desta). Também determinará a inserção do trabalhador nos diferentes gêneros da produção, por exemplo, a separação entre o trabalho manual e 
o intelectual, e entre outras modalidades. Assim, o modo de produção definirá o acesso à produção e ao os meios para produzila que se darão de forma diferenciada, devido à estratificação social.

Quanto às relações sociais de produção - elas são modificadas pelas forças produtivas -, correspondem às formas como os homens se apropriam e transformam natureza. As relações sociais de produção expressam as formas de organização do homem no processo produtivo, os modos como produzem (e o que produzem); as formas de apropriação dos insumos necessários à produção, e como a produção é distribuída, ou seja, a forma como os homens atuam coletivamente ao produzir. Há uma relação de reciprocidade processual entre o desenvolvimento das forças produtivas e as relações sociais de produção (Marx \& Engels, 2007; Marx, 1985).

Em A Ideologia Alemã, escrita conjuntamente com Engels, Marx descreve na seguinte passagem o caráter coletivo que envolve a produção, ou seja, a "cooperação" como uma relação social de produção:

A produção da vida, tanto da própria, no trabalho, quanto da alheia, na procriação, aparece desde já como uma relação dupla - de um lado, como relação natural, de outro como relação social -, social no sentido de que por ela se entende a cooperação de vários indivíduos, sejam quais forem as condições, o modo e a finalidade. Segue-se daí que um determinado modo de produção ou uma determinada fase industrial estão sempre ligados a um determinado modo de cooperação ou a uma determinada fase social - modo de cooperação que é, ele próprio, uma "força produtiva" -, que a soma das forças produtivas acessíveis ao homem condiciona o estado social e que, portanto, a "história da humanidade" deve ser estudada e elaborada sempre em conexão com a história da indústria e das trocas. (Marx \& Engels, 2007, p. 34).

$\mathrm{Na}$ sociedade capitalista, a divisão social do trabalho segmentou os indivíduos em classes sociais antagônicas (possuidores/despossuídos), complexificando as relações entre os trabalhadores e a sociedade. Isso porque as relações sociais de produção, segundo Marx, refletem as formas de organização da produção, da distribuição, da posse e dos tipos de propriedade dos meios de produção, de modo que, a reorganização das forças produtivas, produziu o substrato para a estruturação das desigualdades expressas na forma de classes sociais desiguais.

Ao se submeter o trabalhador à divisão técnica do trabalho, através da inserção de linhas de produção e, por conseguinte, promover a especialização técnica da mão de obra, alterando a dinâmica do trabalho, o operário perde o domínio sobre a produção. Por serem interdependestes, com a divisão social do trabalho, as forças produtivas e as relações sociais de produção se modificam mutuamente. Isto confirma o caráter dinâmico, processual e de reciprocidade entre as forças produtivas e as relações de produção.

A relação de determinação recíproca decorre da natureza das forças produtivas e das relações de produção. Conforme pode se observar a partir das duas categorias, tanto as forças produtivas como as relações de produção são aspectos do processo social de produção e desse modo, formam uma unidade. Essa constatação da relação entre forças produtivas e relações de produção como determinação recíproca, permite entender a correspondência e a contradição que Marx assinala como as formas de relação entre forças produtivas e relações de produção. Se, por um lado, na sua reprodução, as relações de produção reforçam o desenvolvimento das forças produtivas e, por outro, o desenvolvimento destas permitem a reprodução ampliada das relações de produção, então há uma relação de correspondência na interação dinâmica e complexa entre as forças produtivas e as relações de produção. (Augusto \& Carcanholo, 2014, p. 21).

Logo, estabelecidas novas estratégias de controle da força de trabalho são promovidos, por um lado, a reconfiguração da acumulação de capital e da produção, por outro, se intensificam as formas institucionais de regulação da relação entre as forças produtivas (a ação sobre a natureza) e as relações sociais de produção (a organização social da produção). Isso porque, na medida em que produzem, os homens atuam coletivamente e cooperam entre si (Marx \& Engels, 2007).

Como afirma Marx, muitas vezes, as formas de cooperação social envolvem interesses egoístas (por exemplo, a acumulação) que resultam a exploração de um homem por outro. Esse é o corolário da sociedade capitalista, dado ao fosso 
social corroborando pela concentração das riquezas. Portanto as relações sociais de produção dizem respeito aos modos como os homens produzem e distribuem a produção/mercadorias e os meios de produção social; as formas como definem o tipo de divisão do trabalho social em uma determinada sociedade e período histórico.

Os modos de produção capitalista implantados na Inglaterra a partir de meados do século XVII - corroborados pela mecanização progressiva da produção -, consolidando-se graças ao acúmulo de capital conquistado através do mercantilismo e da expropriação da mão de obra operária, entre outros fatores. Isto confirma, pois, conforme a tese contida no materialismo histórico dialético, que as forças produtivas que antecederam a sociedade capitalista, modificaram as relações sociais de produção correspondentes, promovendo transformações nas estruturas da sociedade, elucidando o contexto histórico que confirma a teoria da história de Marx.

\section{Considerações Finais}

É inquestionável a atualidade e genialidade da obra de Marx, a despeito disso, conforme aponta Giddens (2005), o ponto de maior fragilidade presente em sua elaboração reside em suas reflexões acerca da superação do capitalismo pelo socialismo através da luta de classes, ideia síntese da concepção materialista da história. Uma concepção que se distancia da visão idealista hegeliana predominante na época - pensada como substrato do desenvolvimento da consciência - mas, uma concepção materialista da história como produto das forças produtivas.

No século XIX, portanto, a partir da concepção de Marx, pode-se afirmar, pela primeira vez, "que o mundo é produto do trabalho humano, como realidade histórica construída coletivamente pelos homens. Também pela primeira vez afirma-se, na filosofia, que o homem é um ser histórico, o que é dado por sua capacidade de trabalho” (Sader, 2004, p. 12). Tal perspectiva promove uma virada epistemológica na forma como pensar a relação sujeito/objeto, indivíduo/sociedade objetividade/subjetividade, enfim, a forma como o conhecimento é alcançado.

No que se refere a sua epistemologia, o conhecimento científico é uma elaboração inteligível da realidade que, por seu turno, envolve teoria e práxis. Na busca de compreensão da sociedade, ele idealiza um método de abordagem, o "materialismo histórico dialético", uma concepção filosófico metodológica, que parte do princípio de que a consciência é determinada pela relação do sujeito com o mundo material.

Resta-nos dizer que, a despeito de toda genialidade de Marx, onde busca explicar a complexa dinâmica da sociedade burguesa da época, ele não se atentou à capacidade intrínseca do capitalismo de se reinventar dado à realidade social amalgamada na Modernidade.

Porquanto, uma teoria da história em Marx é possível, e está presente desde a A Ideologia Alemã, como se tem afirmado, posto que pode sintetizada "nos princípios de que as forças produtivas são sociais, de que relações de produção e forças produtivas se determinam reciprocamente, e que o papel das forças produtivas como momento predominante é apenas o de condicionante, de limitador de possibilidades" (Augusto \& Carcanholo, 2014, p. 21).

Sugere-se pesquisas futuras que possam aprofundar os estudos da obra de Marx dada à pluralidade de interpretações contemporâneas sobre a noção de historicidade, algumas “infiltradas” pelo historicismo, isto é, influenciadas por uma filosofia da história hegeliana algo que contradiz a perspectiva materialista.

\section{Agradecimentos}

Os autores agradecem o apoio por parte da Universidade do Estado de Minas Gerais (UEMG) e da Universidade Federal de Viçosa (UFV). O presente trabalho foi realizado com apoio da Coordenação de Aperfeiçoamento de Pessoal de Nível Superior - Brasil (CAPES) - Código de Financiamento 001 e da Fundação de Amparo à Pesquisa do Estado de Minas Gerais (FAPEMIG). 
Research, Society and Development, v. 10, n. 2, e7410212012, 2021

(CC BY 4.0) | ISSN 2525-3409 | DOI: http://dx.doi.org/10.33448/rsd-v10i2.12012

\section{Referências}

Alves, P. C. \& Rabelo, M. C. \& Souza, I. M. (2014). Hermenêutica-fenomenológica e compreensão nas ciências sociais. Revista Sociedade e Estado - Volume 29 Número 1 Janeiro/Abril 2014, 181-198.

Aron, R. (2000). As etapas do pensamento sociológico. Tradução de Sérgio Bath. (5a ed.), Martins Fontes.

Anav, R. V. (2017). O retorno de Karl Marx: a redescoberta de Marx no século XXI. Prefácio de Alexandre Linares. Serpente; Fundação Perseu Abramo.

Augusto, A. G.; \& Carcanholo, M. D. (2014). Ainda sobre a teoria da história em Marx. In. Lutas Sociais, 18(33), 09-22.

Giddens, A. (2005). Capitalismo e Moderna Teoria Social.: Editorial Presença.

Gil, A. C. (2008). Métodos e técnicas de pesquisa social. (6a ed.), Atlas.

Marx, K. (1974). Manuscritos: economía y filosofía. Tradução de Francisco Rubio Llorente. Alianza Editorial.

Marx, K. (1985). A miséria da filosofia. Tradução de José Paulo Netto. Global.

Marx, K. (2004). O Capital: crítica da economia política. Civilização Brasileira.

Marx, K; Engels, Friedrich (2004). Manifesto do Partido Comunista. Martin Claret.

Marx, K.; \& Engels, F. (2007). A Ideologia Alemã: crítica da mais recente filosofia alemã em seus representantes Feuerbach, B. Bauer e Stirner, e do socialismo alemão em seus diferentes profetas. Trad. tradução, Rubens Enderle, Nélio Schneider, Luciano Cavini Martorano. São Paulo: Boitempo Editorial.

Martins, L. M. \& Lavoura, T. N. (2018). Materialismo histórico-dialético: contributos para a investigação em educação. Educar em Revista, Curitiba, Brasil, 34(71), 223-239.

Martins, M. V. (2012). O marxismo não é um historicismo: acertos e limites de uma tese althusseriana. Crítica Marxista, (34), 67-85.

Mocelin, D. G. (2017). Quatro olhares fundadores: pistas para desvendar a sociologia clássica de Marx, Durkheim, Weber e Simmel. CirKula.

Oliveira, M. G. M.; Quintaneiro, T. (2007). Karl Marx. In. Quintaneiro, Tania (Orgs). Um toque de clássicos: Marx, Durkheim e Weber. (2a ed.), Revista e

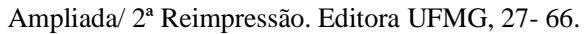

Sader, E. Apresentação. in. Marx, K.; \& Engels, F. (2007). A Ideologia Alemã: crítica da mais recente filosofia alemã em seus representantes Feuerbach, B. Bauer e Stirner, e do socialismo alemão em seus diferentes profetas. Trad. tradução, Rubens Enderle, Nélio Schneider, Luciano Cavini Martorano. Boitempo Editorial. 